\title{
Traduction et circulation du savoir : le cas des ouvrages français en sciences humaines traduits en Egypte
}

Samah Hassan Abdou NASR

Faculté des Jeunes Filles

Université Ain Shams 


\section{Résumé}

Cette étude s'intéresse à une analyse qualitative des traductions en arabe des œuvres françaises dans le domaine des sciences humaines. Elle montre le rôle de la traduction comme opération de transfert de connaissances. L'étude des flux de traduction par domaines de spécialité a pour objectif de découvrir quels sont les facteurs politiques, culturels ou économiques dont dépend la diffusion des ouvrages français en Égypte au niveau des maisons d'édition et dans le secteur universitaire. La comparaison diachronique du nombre d'œuvres traduites et des secteurs favorisés pourrait expliciter les enjeux et les obstacles de la traduction à l'heure de la mondialisation.

D'autres interrogations portent sur le financement des traductions, le choix des œuvres traduites et le statut des traducteurs. À quelle mesure les citations d'auteurs francophones sont-elles reprises dans les écrits universitaires égyptiens et dans les articles de revues publiées en arabe ? À quel degré la traduction contribue-t-elle à l'appropriation intellectuelle du savoir francophone?

\section{Introduction}

L'étude de la circulation des idées à travers la traduction s'inscrit dans le cadre de la sociologie de la traduction et contribue à l'étude de l'histoire des sciences. Notre objectif est de retracer le déplacement des idées importées dans les ouvrages français en analysant leur présence dans l'espace égyptien afin de mesurer le type d'échange entre les deux aires culturelles. Cette démarche consiste donc à examiner la présence des ouvrages traduits sous forme de citations dans les travaux académiques (thèses, articles dans des revues spécialisées). Il s'agit d'observer aussi leur diffusion en ligne que ce soit dans la presse électronique ou sur les forums. Un autre point de cette recherche porte sur le secteur des livres et vise à recenser les études critiques et les publications qui ont abordé les textes originaux. 
La présente étude concerne une réflexion sur les traductions des ouvrages français en Égypte dans le domaine des sciences humaines de 1979 à 2015. Elle inclut les œuvres traduites dans les champs disciplinaires suivants: sociologie, psychologie, histoire, géographie, philosophie, droit, éducation et didactique. Les données sont collectées à partir de l'examen des catalogues de l'Union des bibliothèques des universités égyptiennes, de quelques maisons d'éditions égyptiennes, du site officiel du Conseil national pour la traduction, de l'Index Translationium de l'UNESCO et de quelques sites gratuits de lecture de livres ${ }^{1}$.

Nous souhaitons découvrir dans quelle mesure la traduction influence les sciences humaines au niveau de la circulation des textes fondateurs parmi les universitaires égyptiens de façon à contribuer au renouvellement de la recherche. Ces textes de type scientifique voyagent d'une culture à une autre à quels prix et dans quel contexte ?

Plusieurs études ont déjà abordé la traduction au niveau de la langue arabe. Du point de vue du lien entre les flux de traduction et l'histoire des sciences, certains chercheurs ${ }^{2}$ ont abordé la traduction en tant qu'une activité centrale qui permet de circonscrire les rapports entre les langues et les diverses sociétés. On évoque ces relations en termes de transfert, de dépendance, de dialogue de cultures, d'hégémonie ou d'inégalité des échanges culturels. Ces recherches prennent pour objet les différents facteurs sociaux de la traduction en examinant le procédé en tant que médiation sur le marché du livre. Les études portent sur les enjeux culturels, sociaux, économiques et politiques de la traduction, ainsi que l'approche des acteurs sociaux dans ce marché.

1 La liste des sites internet est indiquée dans les annexes. 2 CALVET 2007, SAPIRO 2014 


\section{La traduction comme transfert}

La traduction a toujours été envisagée dans plusieurs études comme échange entre les cultures. Espagne (2013: 2) aborde la traduction comme un des moyens du transfert culturel entre les différents peuples et met l'accent sur l'intérêt d'observer les ensembles des livres et les divers éléments qui constituent les archives des fonds étrangers. Ces archives informent évidemment les chercheurs sur les transferts culturels puisqu' " elles sont généralement organisées suivant un principe de pertinence qui correspond aux représentations de l'identité d'un groupe, la plupart du temps national.»

Le transfert ou passage des objets culturels cause des transformations car le contexte de réception du texte traduit n'est pas le même. L'étude de ces transformations permet de reconstruire les enjeux identitaires qui entrent en jeu surtout dans le domaine des sciences humaines.

L'idée de l'analyse des flux de traduction est au cœur des recherches actuelles portant sur la sociologie de la traduction : les livres traduits sont l'indice sur les rapports entre les langues et par conséquent la traduction d'une langue A vers une langue $B$ est le signe d'une certaine hégémonie culturelle de la première. Par exemple, Jacquemond $(1993,2007)$ soulève la question d'inégalité des rapports Nord- Sud et dénonce le faible échange de l'arabe vers le français. Il s'est surtout centré sur le champ littéraire égyptien et sur les traductions arabes de Bourdieu. Cette faiblesse est due à la marginalisation de la culture arabe.

D'autres chercheurs envisagent la traduction comme un processus de médiation du savoir. Les échanges dépendent du statut culturel et du rayonnement d'une civilisation à un moment donné. Dans cette optique, l'étude de l'histoire des traductions 
est le miroir du positionnement scientifique d'une société. Dans son étude sur les effets de la traduction sur l'histoire des sciences et surtout après la mondialisation, Calvet (2007: 51) signale que " l'histoire de la science en arabe nous montre donc le rôle central de la traduction, cette médiation sans laquelle toute recherche, toute culture se referme sur elle-même et végète. Si cet enseignement nous a permis d'évoquer un possible déclin des cultures qui ne traduisent plus, qui ne sont plus la cible mais uniquement la source de traductions, il ouvre également sur une ultime conclusion. Si la science arabe devait à nouveau occuper une place de premier plan, ce ne pourrait être qu'après une vaste politique de traduction vers l'arabe, d'adaptation néologique, de travail de la langue.»

Ainsi l'étude de la circulation des savoirs à travers la traduction s'avère indispensable pour découvrir les centres d'intérêt d'une certaine aire aux niveaux culturel et scientifique, notamment en tenant compte des types d'ouvrages traduits et de leur réinterprétation dans la culture - cible. Sapiro (2012) indique que « du point de vue épistémologique : en sciences humaines et sociales, la traduction constitue un enrichissement parce qu'elle favorise la réflexivité et conduit à dénaturaliser les catégories de la pensée, parfois issues du sens commun - elle constitue ainsi un garde-fou contre la standardisation de la pensée.»

En effet, l'évolution de la pensée arabe moderne s'est divisée en deux courants antagonistes: le premier consiste à montrer une plus grande ouverture sur l'Autre et calquer son progrès et sa pensée, tandis que le second incite à se replier sur soi et imposer son idendité qui repose sur les gloires historiques innées dans la civilisation arabe ${ }^{1}$. L'ouverture se traduit par conséquent par la traduction des ouvrages considérés comme une

${ }^{1}$ Cf. 'Abd Allāh Ibrāhīm (2003), Centralisme occidental, Beirut, Al-Muasasah al-'arabiyah lil-dirasāat wa al-Nashr. 
illumination et un renouvellement de la pensée arabe. Après un certain temps se développent des études critiques basées sur des relectures plus élaborées des concepts véhiculés par les spécialistes que ce soient des penseurs ou des chercheurs académiques.

La traduction est conçue selon l'approche sociologique comme capital culturel. Les études sur les courants de traduction reposent sur l'observation des taux d'échange dans l'objectif de mesurer la position de l'espace national sur la scène mondiale. Moghith (1997: 90) a étudié la traduction du marxisme en Égypte et les enjeux idéologiques qui ont dominé l'époque du début du XX siècle aux années 1970, et il conclut «que les traductions, malgré l'appartenance des traducteurs à des horizons idéologiques différents, portent la marque de leur engagement nationaliste. En effet, ce que les intellectuels progressistes égyptiens cherchaient à travers ces traductions, c'était un soutien à leur lutte pour la libération nationale plutôt qu'une assise pour la révolution prolétarienne.»

L'examen des traductions faites du français vers l'arabe en Égypte concerne l'opération traduisante dans l'optique de la mesure du transfert culturel et prend en compte une réflexion sur les enjeux de ce transfert. Dans un premier temps, il semble nécessaire de s'interroger sur la nature des ouvrages traduits. Le choix d'une œuvre ou d'un auteur est certes justifié par des éléments variés que nous essayerons de déchiffrer dans un deuxième temps.

\section{Typologie des œuvres traduites}

Dans son étude sur la traduction d'ouvrages français des sciences humaines et sociales aux États-Unis, Sapiro (2012) précise que "la sélection des livres s'opère selon deux principaux critères : le nom de l'auteur, à savoir son capital 
symbolique (tous les ouvrages des auteurs de la French Theory ${ }^{1}$ sont automatiquement traduits) ; l'intérêt du thème (par exemple, les éditeurs américains s'intéressent particulièrement à tout ce qui touche à l'islam).»

En ce qui concerne le marché du livre en Égypte, la traduction dépend de plusieurs facteurs généraux tels que la faible rotation des objets culturels, le faible investissement dans l'édition et le recul des taux de distribution surtout après la globalisation des ressources électroniques gratuites (open sources). D'autres éléments sont spécifiques à la traduction comme les droits d'auteurs, le contrôle étatique et la domination de la traduction de l'anglais à l'heure de la mondialisation et du monopole des États-Unis.

Selon Jacquemond (2014: 15), les choix de traduction dans les sciences humaines dans le monde arabe en général " reflètent, avec un temps de retard plus ou moins marqué et une certaine sélectivité, les modes intellectuelles dominantes dans les grands centres, en particulier les États-Unis : le structuralisme français et la French Theory ont dominé les années 1980 voire au-delà (Barthes, Foucault, Lévi-Strauss, Todorov, etc.), puis le champ intellectuel arabe a découvert Bourdieu et Ricœur, tandis qu'aujourd'hui dominent les théories critiques anglo-saxonnes (études postcoloniales notamment).» La traduction de ces auteurs s'est d'abord introduite aux États-Unis avant d'attirer l'attention des traducteurs égyptiens et de faire partie de la sphère intellectuelle. Il ajoute que dans le domaine de l'Histoire, Fernand Braudel et Paul Veyne ont été traduits en vue d'une possibilité de participer à la mutation des écrits historiques dans le monde arabe. 
Certains ouvrages sont indiqués comme une nécessité au spécialiste et au non spécialiste à cause de la mutation qu'ils présentent à notre esprit dans notre monde actuel. Cet argument est également avancé par Magda Abaza (2000), traductrice du livre Sociologie des sciences de Dominique Vinck. Elle insiste dans la quatrième de couverture sur l'innovation qu'introduit l'auteur en suivant une nouvelle approche sociologique des sciences : il ne faut pas laisser de côté l'impact de la politique, des courants idéologiques et des intérêts économiques en rapport avec la prétendue science pure. Le livre est la clef pour comprendre les secrets de la production de la science et le rôle des différentes institutions savantes ainsi que les réseaux sociaux actifs. En effet, tout traducteur incite le lecteur à s'approprier le livre en valorisant son contenu et en explicitant l'apport culturel ou scientifique de sa lecture.

Le directeur du Centre national de la traduction (Al Markaz alqawmi lill-tarjama), Moghith ${ }^{1}$ indique que la sélection des livres à traduire dépend de plusieurs facteurs et les traducteurs jouent un rôle essentiel dans le choix des ouvrages. Certains choix émanent des propositions des traducteurs, alors que d'autres résultent des travaux de comités de lecture.

Dans le cadre de notre recherche, nous avons essayé de revoir les titres traduits dans le but de donner un aperçu des différents types de connaissances. Nous avons consulté les catalogues informatisés qui offrent la possibilité de consulter les notes bibliographiques par sujet et selon la classification Dewey. Dans la rubrique des généralités, nous avons retrouvé les ouvrages biographiques, des livres de philosophie générales ; les noms de Descartes, Cresson, Blondel, Bastide, Cuvillier, Politzer, Renan, Bréhier figurent dans la liste des ouvrages traduits dans

April 2016

${ }^{1}$ Dans une interview de la revue Rosalyoussel, le 10/12/2014, http://www.rosaelyoussef.com/news/126546

Vol. 44 
les années 1950-1960. Il faut toutefois noter quelques remarques sur l'index Translationum :

- la base de données permet des interrogations sur les traductions dans un couple de langues par mot-clef du titre, par une année, par éditeur, par traducteur ou à travers une période temporelle déterminée ;

- la recherche peut se faire aussi par le nom d'auteur ;

- les données peuvent s'afficher par sujet ou thème (champ disciplinaire) ;

- le nombre de résultats obtenus est mentionné.

Il est à noter que cette base s'arrête en 2009. C'est pourquoi, nous avons dû compléter notre enquête par la consultation d'autres ressources telles que les catalogues du Centre national de traduction et de la Bibliothèque Centrale de l'université du Caire en plus du site de l'union des bibliothèques des universités égyptiennes.

L'examen des œuvres traduites collectées à partir de notre corpus bibliographique englobent différentes catégories qui peuvent être classées comme suit :

- Ouvrages sur le patrimoine culturel français

Exemple: Braudel, Fernand, (1999), Hawīyat Faransā: almakān wa-al-tārīkh / Al-Sibāî, Bashīr, Le Caire, Al-Majlis alAlā lil-Thaqāfah [Egypt], 1999. 1 v. L'identité de la France: espace et histoire

Braudel, Fernand, (1994). Al-ḥaḍārah al-mādiyah wa aliqtișād wa al-rāsmāliyah min q. 15 ilā q. 18, traduit par Mahir, 
Mușțafā, Le Caire, Dār al-Fikr al-Arab̄̄, 1994. Civilisation matérielle, économie et capitalisme XVe-XVIIIe siècle.

Prédal, René, traduit par Khalil, Suzanne, Le Caire, Al-Markaz al-Qawmī lil-Tarjamah, 2015. 880 p. «50 ans de cinéma français »1945-1995

- Ouvrages sur le patrimoine culturel arabe ou égyptien

Exemple: Fargette, Guy, Muḥammad Alī : Muassis Mișr alhadīthah traduit par Awwād, Muḥammad Rifat, Le Caire, AlHay'ah al-Mișrīyah al-Āmmah lil-Kitāb, 2005

Franco, Isabelle, Mujam al-asāțīr al-Mișrīyah traduit par Jiwījātī, Māhir, Le Caire, Dār al-Mustaqbal al-Arabī, 2001. 364 p. Nouveau dictionnaire de mythologie égyptienne

- Etudes historiques sur l'Egypte et sur les relations francoégyptiennes

Exemple: Raymond, André, Al-Mișriyyūn wa-al-Faransiyyūn fì Le Caire 1798-1801, traduit par Al-Sibāī, Bashīr, Le Caire, Ayn lil-Dirāsāt wa al-Buḥuth al-Insānīyah wa al-Ijtimāīyah, 2001.

Moiret, Joseph-Marie (2000) Mudhakkirāt ḍābiṭ fĩ al-ḥamlah al-faransīyah alā Mișr traduit par Mahmūd, Aḥmad, Le Caire, Al-Majlis al-Alā lil-Thaqāfah. Mémoires sur l'expédition d'Egypte

\section{Ouvrages en sciences humaines et sociales}

Exemple: Hentsch, Thierry (2005), Al Sharq almutakhayyal : ruyat al - Gharb ila al- Sharq alMutawassitī, traduit par Ghaz̄̄ Birrū, Khalīl Aḥmad Khalīl, Le Caire, Al-Majlis al-Alā lil-Thaqāfah, 470 p. L'orient imaginaire: la vision politique occidental de l'Est Méditérranéen.

\section{Ouvrages biographiques:}


Exemple: Lacouture, Jean (2000), Champolion : une vie de lumière, traduit et préfacé par Nabil Saad, Le Caire, Al-Majlis al-Alā lil-Thaqāfah.

\section{Encyclopédies et dictionnaires:}

Exemple: Lalande, André (1996), 3 tomes, Mawsou'āt Lalande Alfalsafiya, traduit par Khalil, Ahmad Khalil, Beirout, Manchourāt Owaydāt.

\section{Ouvrages de philosophie et de psychologie:}

Dans cette catégorie, les livres sont traduits en arabe du français ou de l'anglais. Le point essentiel est le sujet, c'est-àdire que l'écrivain traite un philosophe français en le commentant ou en le critiquant. Les exemples suivants illustrent ces choix :

Bachelard, Gaston (1985) La philosophie du non, essai d'une philosophie du nouvel esprit scientifique, traduit par Khalil, Ahmad Khalil, Dār Al-hadatha.

Copleston, Frederick (2013) Histoire de la philosophie,Tome 4, La philosophie de Descartes à Leibnitz, traduit et préfacé par Tawfik, Saeid et Ahmad, Mahmoud Sayed, Le Caire, Al-Markaz al-qāwmi Lill-tarjamah.

Garaudy, Roger, (1983) Naẓarāt ḥawl al-'insān, traduit par Huwayd̄̄, Yaḥyā, Le Caire, Al-Majlis al-Alā lil-Thaqāaah. Perspectives de l'homme.

Le Bon, Gustave (2012) Al-ārā al-dīniyah wa al-mutaqadāt, traduit par Zītar, Ādel, Le Caire, AL-Mațbaah al-Așriyah, Les opinions et les croyances: genèse-évolution.

Norris, Christopher (2002), Deconstruction: Theory and practice, traduit de l'anglais par Hussam Nayel, Le Caire, le Centre national de traduction.

Rousseau, Jean-Jacques (2009), Așal al-tafāwut bayn al-nās, traduit par Zi'ītar, Ādil, Le Caire, Sharkat Nawābigh al-Fikr. 
Morali Daninos, André (1979), 'Ilm al-nafs al-tațbīqī, traduit par Abd Allāh, Șūfí; Lūqā, Naẓmī / Le Caire, Dār Nahḍat Mișr lil-Ṭibāah wa al-Nashr wa al-Tawzī. La psychologie pratiquée

Descartes, René (1980), Al-Taamulāt fì al-falsafah al-ūlā, traduit par Amīn, Uthmān, Le Caire, Maktabat al-Anjlū alMișrīyah. Méditations métaphysiques

Sartre, Jean-Paul (2001) Nažarīyah fī al-infiālāt, traduit par Al-Qaffash, Abd al-Salām; Alī, Sāmī Maḥmūd, Le Caire, AlHay'ah al-Mișrīyah al-Āmmah lil-Kitāb. Esquisse d'une théorie des émotions.

Ouvrages de sociologie

Durkheim, Émile (1988) Qawāid al-manhag fĩ ilm al-ijtimā, Qāsim, Maḥmūd, Al-Iskandarīyah, Dār al-Marifah al-jāmiiyah. Les règles de la méthode sociologique Reibel, Roger; Rongere, Pierette, (1980) Al-Ishtirakīyah wa alakhlāq, traduit par Salāmah, Lațîf Mușțafā, Le Caire, Maktabat al-Nahḍah al-Mișrīyah. Socialisme et éthique

À la suite de cet aperçu des ouvrages traduits et de leurs divers types, les résultats indiquent que les traductions à partir de la langue française qui datent de 1979 à 20151 sont très variées et elles sont issues de divers champs disciplinaires et concernent les spécialités suivantes: philosophie, psychologie, sociologie, droit, histoire, géographie, art, éducation et religion. En ce qui concerne la typologie des discours, la liste regroupe des essais critiques, des livres, des études. Le recensement des livres est indiqué par spécialité, à partir de Translationum et porte sur trois domaines que nous avons classés dans le tableau suivant:

\footnotetext{
${ }^{1}$ Ces chiffres sont formés de titres recensés dans l'index Translationum et à partir des catalogues de l'union des bibiothèques universitaires, du site du Centre national de traduction et de la maison d'édition Dar Ain.

April 2016 157

Vol. 44
} 


\begin{tabular}{|l|l|l|l|}
\hline Période & $\begin{array}{l}\text { Sociologie, } \\
\text { droit, éducation }\end{array}$ & $\begin{array}{l}\text { Philosophie, } \\
\text { psychologie }\end{array}$ & $\begin{array}{l}\text { Histoire, géographie, } \\
\text { biographie }\end{array}$ \\
\hline $1979-1990$ & 14 & 12 & 7 \\
\hline $1991-2000$ & 25 & 10 & 41 \\
\hline $2001-2009$ & 33 & 21 & 45 \\
\hline Total & 72 & 43 & 93 \\
\hline
\end{tabular}

Nous remarquons que le nombre de traductions a augmenté dans les trois domaines et que les secteurs des études en histoire, géographie et biographie est le plus croissant. Dans le domaine sociologique, les traductions ont doublé.

Le domaine de la philosophie et de la psychologie se caractérise par un recul. Toutefois, malgré cette réalité au niveau de l'édition des traductions, l'étude de la circulation des ouvrages philosophiques démontrera que les lectures des philosophes français et ensuite l'analyse de l'application de leurs concepts s'imposent dans les recherches philosophiques égyptiennes contemporaines.

En général, la traduction d'ouvrages critiques mettent en avant le nom de l'auteur original et le titre traduit, mais ne mentionne ni l'éditeur, ni la langue du texte d'origine. Toutefois, certains traducteurs comme Moghuith et Maher indiquent les notices bibliographiques du texte d'origine.

La réédition des traductions est un aspect à ne pas négliger dans cette étude, puisqu'à notre avis c'est le signe de vie et d'actualité du contenu de ces textes et d'une reconnaissance de leur apport culturel dans le patrimoine international. Les traductions de Zìtar, le grand traducteur et penseur palestinien ont été rééditées plusieurs fois. Elles concernent les travaux de l'orientaliste français Gustave Lebon. Al Hay'a Almasriya alāmā lill-Kitab a créé le projet de Maktabat Al-Osra et a publié le livre La civilisation des arabes en 2000 . Ce projet visait à présenter à petits prix les chefs-d'oeuvre de l'histoire, de la philosophie et de la pensée pour démocratiser l'achat des livres et April 2016 
la diffusion des connaissances dans les sphères publiques. Dans les premières pages des publications du Centre national de traduction, nous retrouvons l'objectif d'offrir au lecteur arabe les différents courants et doctrines au niveau de la pensée.

Cette motivation idéale de médiation ne doit pas nier que cette tâche n'est pas aisée: les textes présentent certaines ambiguités terminologiques, syntaxiques ou stylistiques. Le traducteur est censé surmonter la structure quasi-énigmatique du discours de quelques auteurs et se munir d'une documentation et d'un savoir-faire. La situation se complique quand les termes ne figurent pas dans la langue cible mais est-ce le seul problème en question?

\section{Difficultés de la traduction en sciences humaines}

Berrichi (2012:22) souligne l'importance accordée au transfert des concepts et des théories d'une culture à une autre, car « il ne s'agit pas uniquement de traduire une langue: le traducteur en sciences sociales est en effet amené à retranscrire des concepts. Pour cela, il doit se constituer une bibliographie solide pour surmonter les difficultés inhérentes non pas à la langue source, mais au discours de l'auteur.» Il en résulte une préférence pour un traducteur qui est spécialiste du domaine ou d'un auteur. Il est indispensable de maîtriser la documentation, la recherche de termes, le questionnement et la concertation de collègues. À ce titre, son travail consiste à prendre en considération le contexte de réception des œuvres dans la culture cible.

Un autre problème s'impose lors du passage des termes d'une langue à une autre, celui de la création de la terminologie équivalente dans la langue cible. Dans le cas des sciences 
humaines, certains termes se rapprochent de la langue générale et posent des ambiguïtés. Prenons le cas du terme «déconstruction» dans les ouvrages de Derrida. Ce terme a été traduit en arabe par plusieurs équivalents selon les différentes traductions concernant la pensée du philosophe; Atteya (2008) indique les tentatives de traductions arabes : التفكيك / التفكيكية / اللابنائية/ التقويضية /الدهب التفكيكى . L'existence de ces variantes reflète la grande liberté des traducteurs et par conséquent la responsabilité de participer à cette opération de création terminologique.

Parmi les obstacles auxquels les traducteurs font face, il faut noter que le discours des auteurs - qu'ils soient philosophes, penseurs, chercheurs ou autres - n'est pas simple à assimiler. Sapiro (2012) fait remarquer que " l'écriture des sciences humaines et sociales est moins formalisée que les sciences de la nature, elle implique une dimension historique, fait place à la narration, recourt parfois à un langage littéraire, métaphorique, à des jeux de mots qui peuvent la rendre, sinon intraduisible, en tout cas difficile à transposer dans une autre langue.»

En ce qui concerne la production scientifique dans ce secteur, elle peut se présenter sous forme de livres, d'articles de revues ou de chapitres dans un ouvrage collectif. Ces supports variés se caractérise par des spécificités au niveau de la taille, du type de discours, du public cible, etc. Le statut du français est actuellement critique puisque la tendance générale dans les universités encourage les spécialistes à publier en langue anglaise par souci d'une meilleure visibilité scientifique. Or, les instances culturelles telles que l'Institut français se place du côté du 
maintien du multilinguisme et de la survie de la langue française comme langue du savoir.

Les problèmes terminologiques sont souvent soulevés dans le domaine des sciences humaines et sociales. L'examen des commentaires des spécialistes sur la traduction nous informe sur la révision continuelle des anciennes traductions des termes et le besoin de présenter de nouvelles propositions. Par exemple Choukri(1998) ${ }^{1}$, dans son article pour pésenter l'anthropologue Van Gennep, cite les équivalents arabes pour les termes légende et mythe dans une note. Les chercheurs sont les premiers utilisateurs des ouvrages traduits puisqu'ils les utilisent dans leurs références bibliographiques. Toutefois, les professeurs possèdent une ou deux langues étrangères, ce qui leur offre la possibilité de lire directement dans cette langue. Cependant, les notices bibliographiques des études examinées indiquent que les lectures se font dans la langue maternelle, l'arabe et dans les langues originales des textes fondateurs (anglais et français). Les références en langue française relèvent des champs de la sociologie, de la psychologie, de l'histoire et de la critique littéraire ${ }^{2}$. N'oublions pas aussi que les français reprennent dans leurs écrits les idées de philosophes allemands. Ces allers-retours entre les deux cultures exigent de la part du traducteur une certaine érudition et c'est pourquoi ce n'est pas tout le monde qui traduit la philosophie. La création des termes s'impose car on est toujours en face d'une pensée étrangère qui dépend d'un contexte spécifique.

\footnotetext{
${ }^{1}$ CHOUKRI montre les nuances dans l'emploi des équivalents arabes ce qui relève de la nécessité d'une terminologie précise ou d'un glossaire à insérer dans les traductions. « Mythe "تمييزا لها عن "أسطورة Legende "حكمت كلمة "حكاية

${ }^{2}$ Le structuralisme et la postmodernité ont profondément marqué la pensée arabe moderne April 2016 
Il faut noter que les penseurs et auteurs égyptiens, en tant que médiateurs des sciences et de culture, sont souvent concernés par la précision des termes et de leurs définitions. Le transfert des connaissances comporte des réalités historiques qui ne sont pas familières au lecteur arabe. Par conséquent, ils se trouvent dans l'obligation d'expliciter sens de ces réalités afin d'en assurer la compréhension. L'historien académique, Hussein Moonis ( 1977: 44) confirme le choix de l'équivalent عصر الأنوار pour traduire l'Age des lumières en indiquant ce que désigne le terme exactement et les termes équivalents dans les autres cultures européennes (Die Aufklärung en allemand et enlightment en anglais). Cette attitude pourrait s'interpréter comme une sorte d'érudition et un souci de circonscrire une période si riche.

De son côté, Tolba (2005) précise dans la préface de sa traduction de Derrida plusieurs difficultés qu'elle a essayé de surmonter durant ce travail. En fait, elle mentionne que les phrases du texte source sont très longues. Gauvin avait déjà évoqué ce qu'il a appelé le problème du déchiffrement du discours de philosophie systématique (1971: 88), et il met en accent l'importance de la préface ou de l'introduction dans laquelle, «l'auteur du livre prend d'ordinaire position par rapport à l'actualité — ou la tradition - philosophique. Il a conscience de l'immersion de son oeuvre dans une histoire dans laquelle elle doit se situer. Ce qui paraît bien indiquer qu'il n'est pas possible d'aborder la lecture d'un ouvrage philosophique sans être préalablement en possession d'une culture philosophique plus ou moins étendue.» Selon cette vision, le lecteur doit assumer sa responsabilité de s'approprier le sens du texte et de saisir le système de connaissances qui forment en fin de compte une unité conceptuelle autour de laquelle elles gravitent.

Cette difficulté de déchiffrement se fait suivre de plusieurs lectures. S'ensuit-il que les chercheurs en philosophie et les April 2016 
penseurs sont dans ce sens seraient les meilleurs médiateurs chargés de transposer ce type de connaissances ? Nous essayerons pour trouver des réponses à cette interrogation d'inventorier les traducteurs qui figurent dans notre corpus bibliographique.

\section{Profil des traducteurs}

Pour ce qui est du profil des traducteurs, l'examen des noms et professions des traducteurs avait comme objectif de répondre à la question suivante : qui traduit en sciences humaines en Egypte? Il s'agit donc de voir de près leur formation et le rapport qu'ils ont avec la langue française et la langue de spécialité ou le champ disciplinaire dans lequel ils puisent leurs ouvrages.

Le domaine des sciences humaines comprend différentes spécialités et exige de grandes compétences de la part des traducteurs qui fournissent des efforts et passent beaucoup de temps à réaliser leur travail. Les délais temporels sont plus ou moins longs allant de quelques mois à une année selon plusieurs éléments à savoir : l'expertise du traducteur, sa familiarité avec le champ disciplinaire, le degré de difficulté du texte, l'écart ou le rapprochement du contenu par rapport à la culture cible.

La liste des noms de traducteurs que nous avons rassemblés à partir de notre corpus regroupe les catégories suivantes :

- professeurs des universités dans le champ disciplinaire concerné ;

- professeurs des universités dans les départements de langue et de

littérature françaises ;

- traducteurs spécialisés ;

- traducteurs généralistes. 
La première catégorie se taille une grande part dans le corpus et les maisons d'édition reconnaissent leur valeur scientifique en tant que garant d'une traduction de qualité qui assurerait la bonne diffusion des ouvrages traduits au niveau des chercheurs et du grand public et donc un profit certain.

« En effet, pour bon nombre d'universitaires, le fait de confier ce travail à des traducteurs professionnels non spécialistes n'est pas souhaitable. Est notamment avancé l'argument que de nombreuses traductions réalisées par des linguistes non spécialistes du domaine sont extrêmement décevantes, les traducteurs passant alors fréquemment à côté de concepts et notions clés et ne saisissant pas réellement les tenants et aboutissants du sujet abordé par l'auteur. » ( Berrichi 2012)

Certains traducteurs/ chercheurs ont soutenu des thèses dans des universités françaises tel que ASFOUR, ATTEYA, El KORDY, GHONEIMY HELAL, MOUGHUITH, TOLBA. Ces professeurs universitaires se sentent dans l'obligation de faire le lien entre leurs études portant sur des philosophes ou sociologues français et la pensée arabe moderne et contemporaine. Leur médiation se fait dans un cadre académique ou sous une forme plus simple dans des articles de vulgarisation rédigés en arabe.

D'autres traducteurs sont indépendants, citons par exemple Bashir El-Siba 'i (poète et traducteur); il traduit dans le domaine de l'histoire et de la sociologie. ${ }^{1}$ Cette catégorie de traducteurs se donne plus de liberté en choisissant des ouvrages et en les proposant à certaines maisons d'édition.

En général, la traduction dans ce domaine est assumée par des traducteurs qui ne vivent pas de ce métier et qui éprouvent beaucoup d'intérêt et de passion pour leurs traductions. Ceci dit, certaines thématiques en relation avec les champs littéraires, la traductologie, la linguistique, la philosophie sont confiées à des traducteurs universitaires dans les départements de français. La

\footnotetext{
${ }^{1}$ En général, les auteurs -écrivains s'intéressent à la traduction littéraire où ils peuvent
} rendre au mieux la poétique du texte de départ. 
traduction répond à des goûts et à des compétences personnelles qui varient d'une personne à une autre. Cela n'exclut pas les traducteurs professionnels qui sont engagés dans les institutions officielles ou privés en tant que tels. Par ailleurs, la traduction est en relation étroite avec les maisons d'édition dont dépendent la sortie des publications et leur distribution. Le marché du livre est pris en compte et c'est la raison pour laquelle nous aborderons les différents acteurs dans ce secteur.

\section{Réalités éditoriales}

L'éditeur est chargé de sélectionner tel ou tel livre selon des critères esthétiques et/ou idéologiques d'où il est question d'une ligne éditoriale qui répond des différents facteurs économiques et culturels. Parfois, il assume seul la tâche du tri des textes à traduire et dans le cas des grandes maisons d'éditions, un comité de lecture se charge de cette sélection. Chaque éditeur se crée par conséquent « une image de marque et une identité singulières, tout en s'imposant comme le médiateur indispensable entre une œuvre et un marché, dans l'espoir de répondre aux désirs, aux attentes et aux goûts du public.» POIRIER et GENÊT (2014: 15)

L'édition des livres joue un rôle social au niveau de la vie intellectuelle en assurant la survie des idées et le développement des débats culturels dans la société. La traduction en Egypte a connu, selon JACQUEMOND (1991), à l'époque nassérienne «un essor sans précédent de la production de livres traduits - en moyenne, plus de 200 titres par an de 1952 à 1967, contre 30 à 50 dans les années quarante.» Le pourcentage des œuvres traduites du français et de l'anglais était de $90 \%$ de l'ensemble des titres traduits. Cette vague avait comme éléments moteurs la volonté de l'Etat qui finançait la traduction et la publication dans le cadre du projet alf kitâb dans l'objectif de donner aux classes moyennes l'accès à la lecture des ouvrages culturels modernes. 
Les années 1970 ont marqué un recul de la traduction, mais dès 1980 les livres traduits se multiplient sous l'influence des programmes d'aide étrangère tel que le programme américain Book Program et le programme français qui sera connu sous le nom Taha Hussein. En 1986, le projet « Mille livres bis » de la General Egyptian Book Organization relance les opérations de traduction et l'on assiste en 1996 à la naissance du Projet national de traduction relevant du Haut conseil de la Culture. Ces deux institutions monopolisaient l'édition des traductions dans les domaines de la philosophie, la psychologie, les généralités avec un nombre limité d'éditions dans le secteur privé.

Selon l'étude de Varlet (2010), le volume des titres traduits s'accroit à partir de l'année 2000, grâce à la création du Centre national de traduction. Plus de 2000 livres sont traduits jusqu'à 2011 non seulement du français mais d'autres langues selon Jaber ASFOUR ${ }^{1}$.

Les éditeurs privés ont augmenté et nous en avons compté vingt-huit dont la majorité se trouve au Caire et quatre à Alexandrie. Dans les années 1950-1970 la librairie Al -Anglo Almasriyah a joué un rôle important au Caire dans la publication des traductions et à Alexandrie, c'est Dar Alma'ārif Aljamiāh qui en publiait en plus des ouvrages académiques d'universitaires égyptiens traitant les textes fondateurs en sociologie, anthropologie ou psychologie. Les organismes officiels prennent en charge la traduction comme Mūassasat Akhbār al-Yawm, Dār Al-hilal et Dār al-Maārif, la plus ancienne maison d'édition qui a été créée en 1890 par Naguib Mitri et son frère Shafiq, mais qui a été nationalisé par l'Etat dès 1961.

D'autres organismes officiels égyptiens comme Al Majlis Al-a'la lill-Thaqafa (Haut conseil de culture), Hay'at Qușūr al- 
Thaqafah et Al- Hay'a al-ama lill-kutub Al-Masriya, ont financé la publication des traductions et continuent à le faire. De son côté, le directeur du Centre national de traduction a maintes fois souligné le haut coût de traduction surtout les droits d'auteurs français et a annoncé dans une interview ${ }^{1}$ que le centre collabore avec les maisons d'édition privées pour participer aux frais de publication à condition d'imprimer son nom sur le livre. Et concernant le faible taux de traduction vers le français, il a expliqué qu'il œuvre à contacter des éditeurs étrangers pour négocier la publication d'ouvrages traduits de l'arabe afin de mieux assurer la diffusion de ce type de traductions sur le marché européen.

Le Centre national de traduction se charge de rééditer des traductions anciennes en reconnaissant le rôle de certaines œuvres capitales qui ont marqué l'humanité et qui continuent à inspirer les nouvelles générations. Cette opération est mise en application sous le nom d'Héritage de traduction qui permet de rééditer les traductions en littérature mondiale.

Dar Ayn lil-dirasat alijtima'iya publie essentiellement des ouvrages des chercheurs égyptiens et des traductions en sciences humaines; elle a présenté les traductions de plusieurs philosophes et orientalistes français tels que Paul Ricoeur ${ }^{2}$ et Christian Delacampagne ${ }^{3}$ et Gaston Wiet ${ }^{4}$. Les traducteurs sont égyptiens et arabes.

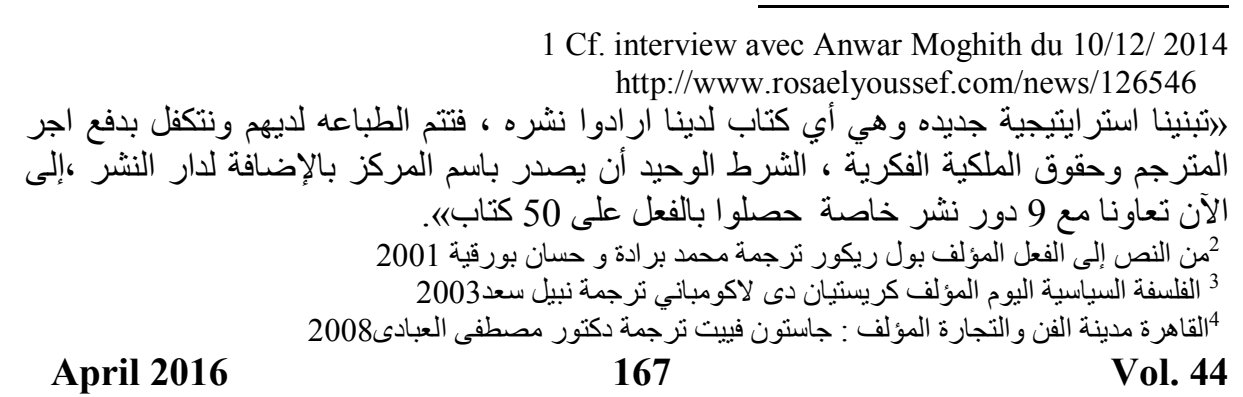


Un autre aspect est à noter, celui de la publication au Liban des traductions faites par des écrivains ou traducteurs égyptiens. Dar Alnahar, Dar Al-tali'a, Almoassassa Alarabiya lill-tawzi'i wal nashr sont parmi les éditeurs qui ont imprimé des ouvrages de philosophie de traducteurs égyptiens ${ }^{1}$.

Récemment, les Emirats-arabes se sont imposés sur la scène de l'édition des œuvres françaises avec l'adoption du projet Kalema qui a souvent recours aux traducteurs égyptiens de renom. Dubaï prend le relais dans le champ de traduction et cherche à se créer une position remarquable en tant que capitale culturelle du Monde arabe.

\section{Les prix de traduction}

Les autorités officielles chargées de promouvoir la traduction y voient une ouverture et un enrichissement et par conséquent des fonds sont fournis pour l'attribution annuelle de prix pour encourager les traducteurs et en tant que reconnaissance de la valeur de leurs efforts surtout dans le cadre des sciences humaines. En Egypte, le Centre national de traduction offre chaque année deux prix: le prix Rifaa El Tahtawy pour les traducteurs experts et un autre prix pour les jeunes traducteurs.

Aux Emirats-arabes unis, le Prix du Cheikh Zayed pour le livre est attribué aux ouvrages dans plusieurs secteurs dont fait partie les ouvrages traduits. L'Egyptien Hussam Nayil, professeur à l'Académie des arts, a reçu ce prix en 2014 pour sa traduction du livre Against Deconstruction, un livre qui critique les idées de Derrida et dont la traduction est publiée par le centre national de traduction.

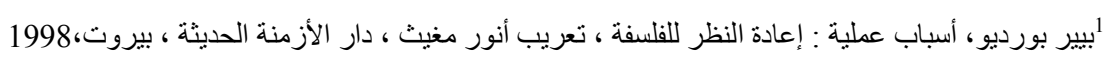




\section{Les traductions de l'Institut français d'Egypte}

L'Institut français œuvre de son côté à asssurer le rayonnement de la pensée et de la culture française, c'est pourquoi il «met en place, avec le réseau culturel français à l'étranger, des programmes de valorisation de la pensée française contemporaine dans le monde, pour promouvoir le débat d'idées via des colloques et des conférences. Il se sert à cet effet du Fonds d'Alembert, conçu en 2002. » SAPIRO (2014 :239)

En Egypte, il a présenté des romans comme Voyage au bout de la nuit de Céline publié 1995. L'institut a pu éditer avec Dar Al-Alam Althalith l'édition de quelques ouvrages du sociologue Pierre Bourdieu traduits par Ibrahim Fathi. Et en collaboration avec l'institution égyptienne du Centre national de traduction, l'IFE a contribué à la publication d'une encyclopédie en plusieurs tomes dans les domaines de sciences sociales et des sciences naturelles. (Yves Michaud, (2001) Université de tous les savoirs, Paris, Odile Jacob.) Elle comporte des titres tels que: Qu'est-ce que la sociologie? Qu'est-ce que les technologies? Qu'est-ce que l'humain? Qu'est-ce que la culture?

Les autres publications concernent des thématiques politiques et des études littéraires comme :

Denis, Benoît, (2000), Littérature et engagement de Pascal à Sartre, Paris, Points Seuil

Schemeil, Yves, (2001), La politique dans I'ancien Orient, Paris, Presses de Sciences-Po.

En ce qui concerne les sciences humaines, il a collaboré avec des éditeurs égyptiens privés. Exemple: Girardet, Raoul (1995) Mythes et mythologies politiques, traduit par Kalfet, Khalil, Dar Al-fikr lill-dirāsāt wa al-nashr wa al-tawzi. 
Il est important de signaler que les mêmes ouvrages ont parfois fait l'objet de deux éditions en Egypte et au Liban, en effet Le Caire et Beirut ont, de tout temps, été deux centres de rayonnement culturel dans le champ de la culture arabe. Il ne faut pas négliger qu'en sciences humaines, Damas et Casa Blanca jouent un rôle dans la traduction du français. Beaucoup de penseurs et de chercheurs égyptiens ont publié des traductions du français pour la série Alam al-Maārifa qui dépend du Conseil national pour la culture et les arts du Koweit. Le début de ce projet date de 1978 et se donnait comme mission l'enrichissement culturel du lecteur arabe. En plus, pour assurer une meilleure visibilité d'un livre, on peut le rééditer plus que deux fois comme celui de Sartre, Qu'est-ce que la littérature?, traduit par Mohamad Ghoneimy. Il a été publié chez:

- Dar Al-‘Awdah, Beirut en 1986 ;

- Dar Nahdat Misr, Le Caire en 2005 ;

- Et Maktabat Al-osra 2005.

Les éditions de Maktabat Al-osra se caractérisent par le faible coût de production qui profite de l'aide du gouvernement égyptien pour présenter la culture à un prix abordable. Leurs publications sont très variées: en plus des romans des grands auteurs français, des ouvrages sur la culture, l'histoire et la philosophie y figurent également.

\section{Les publications du Centre de langues et de traduction de l'Université du Caire}

Notre recherche se base sur les données bibliographiques enregistrées sur le site de la bibliothèque centrale de l'Université $\mathrm{du}$ Caire et sur un fichier renfermant une liste de publications $\mathrm{du}$ 
Centre. Nous avons pu obtenir cette liste en nous adressant au bureau de l'administration du Centre.

Les langues des textes sources de ces traductions ne sont pas mentionnées mais nous avons pu reconnaître quelques noms français. En plus, les noms des traducteurs et traductrices ont un peu guidé. Nous avons trouvé les deux ouvrages suivants :

Wallon, Dominique (2012), Internet et après ?, traduit par Abdel Aziz, Aida, Le Caire, Centre de langues et de traduction de l'université du Caire.

Leclercq, René (2012), Histoire et avenir de la méthode expérimentale, traduit par Taher, Hamed, Le Caire, Centre de langues et de traduction de l'université du Caire.

Le centre publie les traductions à partir d'autres langues : l'anglais, de l'allemand et de l'espagnol. Il s'intéresse à la publication de certaines études rédigées en arabe par des professeurs de l'université comme le livre suivant sur Descartes :

الخشت, محمد عثمان , أقنعة ديكارت العقلية تتساقط, القاهرة, مركز جامعة القاهرة للغات

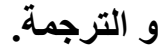

Niveau de réception et de la circulation des ouvrages philosophiques

Après avoir dressé un bilan des traductions collectées, il est temps de montrer quel rapport existe entre le transfert des connaissances et le champ des recherches et de la pensée dans la langue cible. La circulation n'est pas uniquement le transfert des idées mais elle implique un processus d'appropriation en une autre langue qui entraîne une transposition dans un autre contexte et par conséquent suscite des débats et des réactions susceptibles de former des prises de position positives ou négatives. Cet axe de recherche suit la lignée des études françaises portant sur la mesure du positionnement culturel de la France à l'étranger 
surtout dans le domaine des sciences humaines et sociales. Ce point a toujours été un des centres d'intérêt de la politique du ministère français des affaires étrangères. Récemment, une enquête a été lancée afin de mesurer la diffusion des livres français aux États-Unis, au Royaume-Uni et en Argentine.

Précisons d'abord qu'au niveau académique, la constitution des connaissances repose sur des enjeux relatifs à la recherche d'une certaine validation à travers les publications des travaux que Rinck (2010 : 432) appelle le rôle de l'éditorialisation: « le statut scientifique que prennent les savoirs à travers leur éditorialisation est mis en évidence, avec, de fait, un intérêt pour le rôle de validation du savoir joué par sa diffusion, soit au niveau de la sélection et de la révision par les pairs, soit du côté de la communauté des lecteurs directement, à travers les citations.»

Actuellement, l'étude des références bibliographiques est facilitée par la consultation des bases de données qui affichent les citations d'auteurs dans les articles grâce à l'archivage électronique des publications (articles, ouvrages ou chapitres dans des œuvres collectives). L'interrogation porte sur les titres, les résumés et les notices bibliographiques.

La recherche des citations d'auteurs français ou de leurs traductions part de l'idée que ce type de références donne plus de force aux écrits scientifiques; les chercheurs égyptiens veulent donner plus de poids à leurs discours en les situant dans un cadre théorique précis. Le repérage des citations d'auteurs français dans l'espace scientifique égyptien puis son analyse permet de délimiter le taux des savoirs acquis et les débats dans un domaine précis. 
L'introduction des idées importées ne se fait pas sans résistance. Elle est parfois l'objet d'une censure au niveau politique ou au niveau religieux. Dans le champ des sciences humaines, il est question de sciences molles, qui toutefois ont une grande influence sur la pensée et le contexte d'accueil.

Parmi les activités de circulation de certains courants, il est monnaie courante de traduire une interview d'un philosophe ou d'un critique français surtout s'il passe un séjour en Egypte dans le cadre des missions scientifiques au sein des universités égyptiennes ou aux locaux de l'IFE du Caire. Prenons l'exemple de Philippe Hamon, qui a visité Le Caire en mission pour deux semaines à la faculté des Lettres d'Ain Chams. Lors d'une interview par le professeur Hodja Wasfi, il a présenté les problèmes du réalisme et du discours contraint et a donné des applications sur des œuvres littéraires. Son intervention a été publiée dans la revue Fousoul ${ }^{1}$, revue de critique littéraire, en plus d'un article intitulée la littérature $=$ liberté + contrainte .

La célébration de la visite d'un philosophe français coïncide avec le lancement de la traduction d'une de ses œuvres ou bien sa participation à une manifestation scientifique qui s'insère dans la vie culturelle égyptienne comme les activités de L'Institut français. Prenons l'exemple de la visite de Jean Luc Nancy qui a donné une conférence le 27 février 2001 sur L'Occident et le monothéisme que le journal Al-Ahram Hebdo a signalé parmi les événements concernant la société francophone égyptienne.

La mobilité des professeurs a toujours été un des facteurs de la circulation du savoir. Selon Avon (2005: 132), dès sa 
création en 1908, l'Université du Caire a fait appel à des professeurs français dans les facultés de droit et des lettres, et une élite de jeunes chercheurs est choisie pour poursuivre leur formation en France: l'enseignement de la philosophie y est assuré par des Français (André Lalande, Alexandre Koryé, EmileBehrier, Abel Rey, Louis Rougier, Burloud...) bientôt rejoints par des Egyptiens qui bénéficient d'un double itinéraire intellectuel.»

Dans le cadre de ce travail, l'étude de la réception des philosophes français vise à mettre en lumière l'état de la recherche et les problématiques des thèses universitaires en question. Selon LADMIRAL (2006: 135), " le concept de la réception est intéressant dans la mesure où il nous amène à pousser la réflexion théorique sur la traduction assez loin... un texte ne prend tout son sens qu'à la lumière de la réception, c'est à dire de sa compréhension et de son appréciation par un public dont ... l'horizon d'attente évolue au cours de l'histoire». Si nous passons en revue les études précédentes, nous trouvons que l'introduction des théories et des idées entraîne des débats aux niveaux des universitaires et de l'opinion publique. La communauté scientifique les analyse et l'on assiste à des ouvrages qui les critiquent ou qui cherchent à les diffuser.

Dans le domaine de la philosophie, les chercheurs égyptiens ont été fortement imprégnés par les différents courants philosophiques. Certains sont partis en France pour se former et d'autres s'y intéressent dans leurs thèses. Parmi les grands noms, citons Descartes, Sartre, Derrida, Deleuze, Lyotard et Foucault. Nous avons consulté les catalogues des thèses universitaires concernant Derrida et Foucault. L'examen des thèses récentes a permis de délimiter plusieurs thématiques comme par exemple le concept de déconstruction de Derrida, qui a été traité dans les thèses suivantes : 
- Mahfouz, Medhat Safwat (2013), La problématique de la réception des stratégies de déconstruction dans le discours critique arabe, université de Helwan, sous la direction d' ElHaj, Haytham et Abdallah, Mohamad, thèse de magistère.

- Hassan, Marwa Hassan Anwar (2015), Stratégie de déconstruction chez Jacques Derrida: le cas du cogito de Descartes, université d'Ain Chams, sous la direction de Mohamad, Mohamad Yehia Farag et Moharam, Nachwa, thèse de magistère.

Nous avons lancé une recherche sur la déconstruction dans la pensée arabe et c'est le nom du professeur de philosophie à l'université du Caire, Ahmad Abdel Halim Atteya qui s'est imposé. En fait, le suivi de ses publications scientifiques nous informe sur la grande importance de la philosophie française dans sa formation.

Atteya s'est particulièrement intéressé à Deleuze et il a publié sous sa direction un livre intitulé Gilles Deleuze : Les politiques du désir ${ }^{1}$ qui regroupe des articles écrits par des spécialistes arabes sur les travaux de ce philosophe français.

Dans son ouvrage sur Deleuze, Atteya (2011:9) a publié sous sa direction un recueil d'articles sur ce philosophe. Dans la préface, il présente l'influence de sa philosophie sur la pensée arabe moderne en indiquant qu'il n'a pas suffisamment retenu l'attention des intellectuels arabes qu'au cours des dernières années. Dans cette perspective, il s'interroge sur les ouvrages traduits en arabe en le comparant à ses collègues de la post-

${ }^{1}$ 2011, Beirut, Dar Al-Faraby, série awraq falsafia 
modernité tels que Foucault et Derrida. Ensuite, il explique les raisons pour lesquelles il est temps d'aborder ses idées philosophiques originales en citant les différents ouvrages traduits qui portent sur ses écrits, les traductions de ses entretiens ainsi que les articles le concernant dans les revues arabes. Le décalage de la réception de Deleuze dans le monde arabe est dû au grand essor des œuvres de Foucault: l'Archéologie du savoir a submergé les études philosophiques et a influencé le champ littéraire. L'auteur est donc présenté afin de présenter sa vision de la littérature et de l'art et de profiter de ses idées en ce qui concerne la philosophie arabo-musulmane tel que son intérêt pour la philosophie d'Avicenne. Atteya énumère les articles et les études sur l'œuvre de Deleuze et cite aussi une thèse de doctorat sur l'esthétique de l'image. ${ }^{1}$

Dans le même ouvrage, un autre professeur et également traducteur d'ouvrages philosophiques, MOGHUITH (2011: 29) situe DELEUZE par rapport à ses contemporains, au structuralisme de Strauss et présente sa philosophie et sa critique de la psychanalyse.

Les revues philosophiques scientifiques traitent les philosophes français dans des articles. Prenons l'exemple de la revue Awraq Falsafiya ${ }^{2}$ dont le rédacteur en chef est le professeur Atteya de l'université du Caire. Prenons le numéro 5 sur Gilles Deleuze en arabe formé de plusieurs articles qui examinent sa pensée et traitent des points tels que:

- Le discours de l'altérité;

- La philosophie de Deleuze;

1 BADR, M. (2009), L'esthétique de l'image chez Deleuze, thèse de doctorat université du Caire. 
- Le discours de la différence;

- Le texte de Deleuze et l'image du philosophe;

- Deleuze, historien de la philosophie;

- Deleuze et Avicennes.

À part ses articles sur Deleuze, Atteya a publié sous sa direction quelques ouvrages collectifs sur d'autres philosophes comme Lyotard ${ }^{1}$ et sa vision de l'histoire.

Atteya maîtrise la langue française et il lit des références en français et en arabe. La traduction est supposée « dispenser de la lecture de l'original et $[\ldots]$ de permettre aux lecteurs de faire l'économie de l'apprentissage complet d'une langue étrangère »selon Rochlitz (2001 : 65). Cependant, tel n'est pas le cas dans la conception des cursus universitaires égyptiens : dans les filières des sciences humaines, il existe des modules de langue étrangère (français ou anglais) au cours desquels les étudiants sont formés à la lecture et à la traduction de textes de spécialité.

Dans les publications du centre national de traduction, une série appelée «Je te présente» introduit les noms de Derrida, de Foucault, de Baudrillard et d'autres au grand public. La vulgarisation des idées philosophiques est réalisée également à travers les articles des spécialistes dans la presse générale et actuellement sur les sites gratuits de lecture en ligne et sur les forums des amoureux de la philosophie. Le site "Alhiwar almoutamaden" héberge beaucoup d'articles en sociologie et en philosophie et aborde les idées de Bourdieu, de Foucault, etc. Parfois, les médias célèbrent la sortie d'une nouvelle traduction ou présentent brièvement le compte-rendu d'un ouvrage dans le cadre du salon annuel du livre.

Une traduction introduit le traducteur dans le monde du philosophe et la documentation qui va de pair avec la lecture permet 
au premier de s'approprier vraiment les idées du dernier et crée un lien étroit entre les deux de sorte à inciter à la publication d'un livre sur les idées philosophiques acquises ou une biographie de son auteur. Pour illustrer ces propos prenons l'exemple du traducteur Hossam Nayel qui a traduit plusieurs ouvrages publiés par le Centre national de traduction, concernant Derrida et la déconstruction ${ }^{1}$. Il دروس فى choisit de publier un livre sur cette théorie qui s'intitule . التفكيك .

Pour découvrir l'influence des traductions de Foucault et sa présence dans la pensée arabe, son nom apparaît dans les titres et les résumés de plusieurs thèses soutenues dans des départements variés : la philosophie, la langue anglaise, la langue arabe et dans la faculté de sciences politiques selon les références suivantes:

\begin{tabular}{|c|c|c|c|}
\hline الجامعة & الاشراف & اسم الباحث & عنوان الرسالة \\
\hline , دكتوراه جامعة الاداب بـها. قسم القلسفه 2013 & و عبد الخالثق عبد الحفيظ , محمد طية & خضر, أحمد يوسف & اركيولوجيا الصر فلسفة ميشيل دراسة فوكو \\
\hline كلية الاداب ـ قشم القلسفة بنهاه & 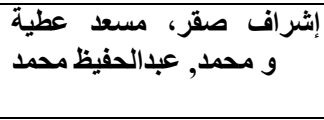 & أبو الصديق الله غيثلة & 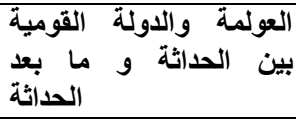 \\
\hline شمس. كلية الاداب ـ قستير, جامعة القلسفه عين & اشراف اسين اسماعيل & محرج, نشلاح الاين & مفهوم السلطه عند ميشيل فوكو \\
\hline 2011 , كليةآداب ـ قستير, جامعة اللغة العربية. حلوان. & 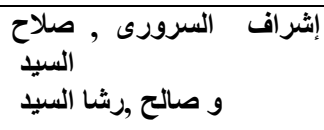 & سـعبد, فاطمة أبو بكر & آليات نقد الاستشراق عند ادوارد سعيد \\
\hline
\end{tabular}

. Norris, Christopher (2002), 1 Norris, Christopher et Spivack, Gayatari (2002), Derrida Deconstruction: Theory and practice. Almond, Ian (2004), Sufism and Deconstruction: A Comparative Study of Derrida and Ibn 'Arabi Timothy, clarck (2011)

April 2016 


\begin{tabular}{|c|c|c|c|}
\hline 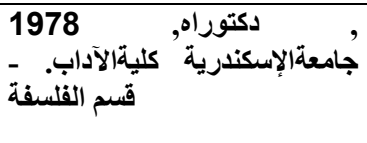 & إثراف محمد على أبو ريانَ, & السبد الوهنب, & المعاصرة \\
\hline 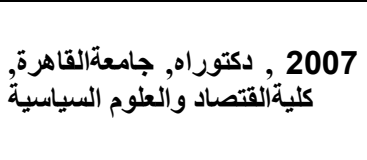 & إشراف السيد ,مصطقى كامل عزلى عمرو & حبش, الورد & 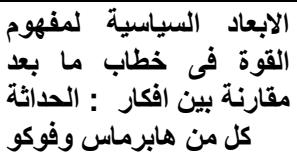 \\
\hline 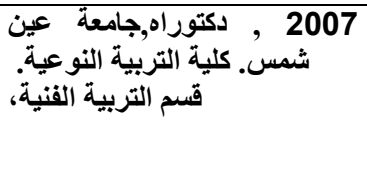 & إشراف مجدى, فريد عدوى & زين الدين, على أحمد & 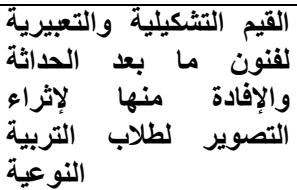 \\
\hline كلية/الاداب ـ قسم اللغة الانجليزية. & 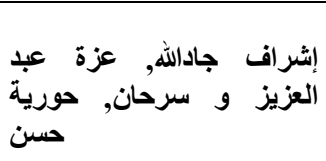 & 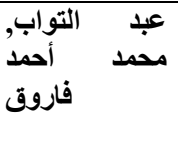 & نظرية الصدمة في اعمال \\
\hline 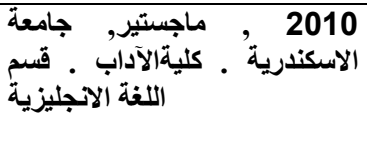 & حمودة , سحر & 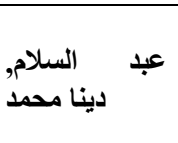 & 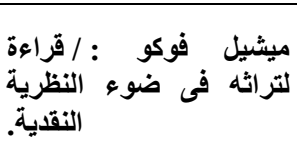 \\
\hline 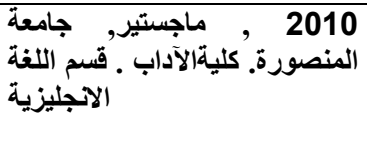 & إشراف سليمان, نادية & السعبنى , رحمد & 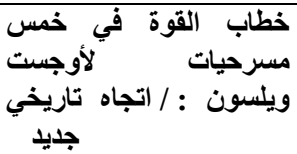 \\
\hline
\end{tabular}

Ces thèses sont non- publiées sauf celle du professeur Gaafar, Abdel wahab qui est éditée par Dar Al-ma'arif Algami'iya à Alexandrie. Après avoir consulté les œuvres de Foucault, cette recherche a montré que son nom figure aussi dans des articles de revues académiques.

Exemples :

$$
\text { حسني إبراهيم عبد العظيم (2008) أستاذ الاجتماع بكلية الآداب بجامعة بني سويف فئي }
$$

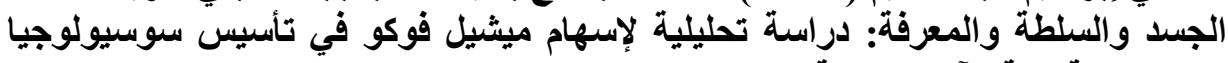
الجسد مجلة كلية الآداب جامعة بني سويف تلبيف 
Sur le site du Centre arabe des recherches et des études ${ }^{1}$ deux articles citent ce penseur:

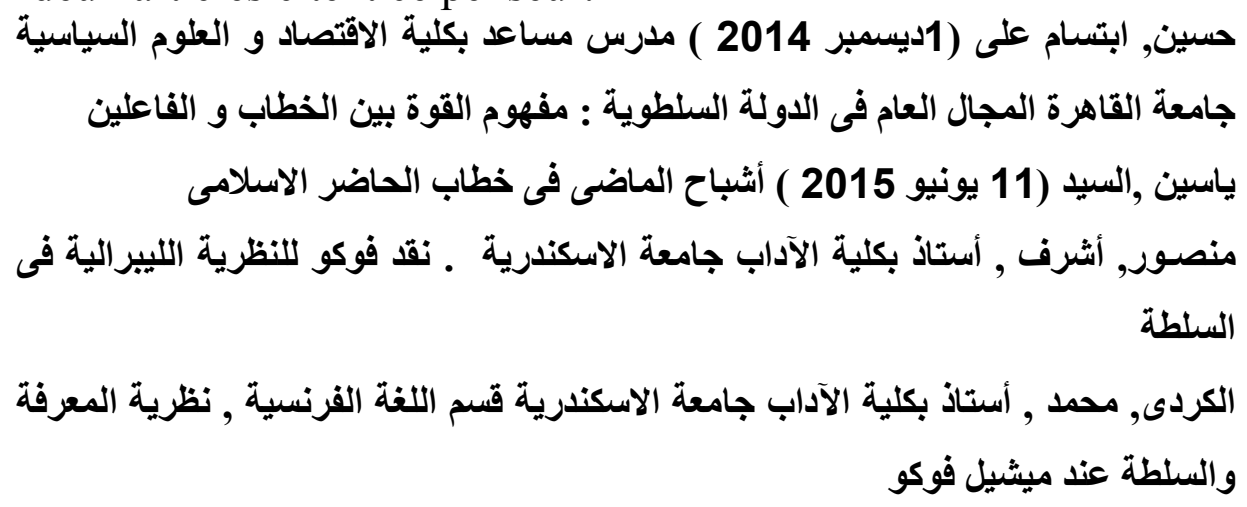

Les citations dans ces travaux indiquent la traduction du livre de Paul Veyne traitant ce même auteur, Foucault révolutionne l'histoire ${ }^{2}$.

Nous en déduisons que les ouvrages traduits de Foucault ont participé à l'examen de ses théories et analyses qui ont été appliquées par des chercheurs égyptiens dans diverses disciplines (histoire, philosophie, politique, linguistique); l'enjeu scientifique de la traduction est de créer des voies entre les idées premières et de mener à la constitution de nouvelles approches dans les champs du savoir. Les chercheurs égyptiens anglophones se réfèrent à des articles en anglais ou en arabe sur la pensée de Foucault.

) http://acresg.org (المركز العربى للدر اسات والبحوث (1) ${ }^{2}$ Traduit par Ibrahim Fathi, Le Caire, Dār al-Fikr lill- Dirasat wa al-Nashr wa al-Tawzī, April 2016 


\section{Conclusion}

Premièrement, les résultats de cette étude ont essayé de répondre à certaines interrogations qui reposent sur la sociologie des traductions et qu'il serait intéressant d'élaborer ultérieurement. La traduction est une clef d'accès aux sciences du monde francophone qui laissent leurs marques dans notre esprit et dans notre pensée. Ce travail a souligné que l'activité scientifique se fait dans des cercles ou dans des réseaux, la preuve c'est qu'un chercheur se centre sur un philosophe et organise par la suite d'autres recherches réalisées par ses disciples. Certains traducteurs-chercheurs approfondissent leur connaissance d'un auteur et publient des articles sur son style, ses idées ou son positionnement par rapport à ses contemporains.

Deuxièment, l'interdisciplinarité de plusieurs ouvrages impose au traducteur une documentation et une recherche terminologique étant donné que les frontières entre termes de la langue générale et des langues spécialisées ne sont pas tranchantes dans les sciences humaines. La publication d'encyclopédies serait un ajout aux ressources dans ce champ et permettrait de standardiser les listes terminologiques et de valoriser les efforts des traducteurs et des spécialistes en créant des voies pour préserver et mutualiser les résultats de leurs travaux.

Les choix des œuvres à traduire devraient s'insérer dans des politiques linguistiques de la culture arabe. En Egypte, les responsables officiels d'édition des traductions ont commencé à coopérer avec les éditeurs privés en vue d'agrandir le volume des traductions. Il reste une étape importante pour harmoniser les efforts nationaux sous forme de bases de données bibliographiques des traductions, classifiées par champ disciplinaire. Une deuxième étape consiste à faire des statistiques 
des ventes et du rapport coût/prix afin de réaliser des profits économiques et poursuivre le financement de ce processus.

La traduction joue un grand rôle dans l'évolution de la recherche scientifique puisqu'elle permet aux non francophones de se familiariser avec de nouveaux concepts. Elle incite aux publications qui sont à notre avis les voix régionales des chercheurs qui se donnent la chance de s'exprimer par rapport aux autres. En sciences humaines, les concepts sont révisés et parfois contredits. L'appropriation du savoir ne se fait pas automatiquement, elle dépend d'acteurs sociaux et culturels dont les traducteurs sont les plus efficaces.

Dans le passé, la traduction de la langue arabe a été la source de la Renaissance de l'Occident : elle était la voie d'accès aux savoirs des Grecs. Pour reconquérir sa place, elle doit être promue par ses propriétaires : le respect de la langue nationale doit se généraliser dans les divers champs disciplinaires, et en particulier dans l'enseignement supérieur, pour encourager l'arabisation et c'est ainsi que la traduction reprendra sa position en atteignant ses objectifs culturels et scientifiques. A l'ère contemporaine, l'accès au savoir est garanti grâce aux autoroutes de l'information, c'est vrai, cependant la visibilité mondiale est régie par d'autres enjeux et reste le monopole de quelques réseaux strictement enchaînés. 


\section{Bibliographie}

ALLARD, O. (2014), «Traduire et introduire les sciences humaines », Tracés, Revue de Sciences humaines, $n^{\circ} 14$, consulté le 23/01/2017, http://traces.revues.org/5986

AVON, D. (2005), Les Frères prêcheurs en Orient: les dominicains du Caire (années 1910-années 1960), Paris, Editions du CERF.

BASTIN, G. et L., CORMIER, M. (2012), « Que fait un traducteur ou une traductrice?», in Profession traducteur, Montréal, Presses de l'Université de Montréal, p.25-38, consulté le 01/12/2017, http://books.openedition.org/pum/267

BERRICHI, A. (2014), « La traduction en sciences sociales », Traduire, $\mathrm{n}^{\circ} 227, \quad$ consulté le 12/02/2017, http://traduire.revues.org/467

BOISSEAU, M. (2016), « De la traductologie aux sciences de la traduction?», Revue française de linguistique appliquée, $\mathrm{n}^{\circ} 21(1)$, p.9-21, consulté le 12/02/2017.

BOURDIEU, P. (2002), « Les conditions sociales de la circulation internationale des idées»», Actes de la recherche en sciences sociales, $\mathrm{n}^{\circ} 145, \quad$ p. 3-8, consulté le 12/02/2017, http : www.persee.fr/doc/arss_0335-5322_2002_num_145_1_2793

BOURGEOIS, B. (2005), « Traduction philosophique et échange culturel », Revue philosophique de la France et de l'étranger, 2005/4 (Tome 130), p. 469-481. DOI 10.3917/rphi.054.0469

CALLON, M., (2006) «Quatre modèles pour décrire la dynamique de la science», in Sociologie de la traduction : Textes fondateurs, Paris, Presses des Mines, p. 201-251, consulté le 02/02/2017, http://books.openedition.org/pressesmines/1199 
CALVET, L.-J. (2007), « La mondialisation au filtre des traductions "), Hermès, La Revue, 2007/3, $\mathrm{n}^{\circ}$ 49, p. 45-57, consulté le 01/11/2016, http:// www.cairn.info/revue-hermes-la-revue-2007-3page- $45 . h$ tm

CASANOVA, P. (2002), "Consécration et accumulation de capital littéraire [La traduction comme échange inégal] », Actes de la recherche en sciences sociales. Vol. 144, septembre 2002. Traductions: les échanges littéraires internationaux. p. 7-20, consulté le $01 / 11 / 2016$

http://www. persee.fr/doc-arss_0335-5322_2002_num_144_1_2804

CUSSET, F. (2003), French theory. Foucault, Derrida, Deleuze et cie et les mutations de la vie intellectuelle aux Etats-Unis, Paris, La Découverte.

DUMOULIN, L., \& SAURUGGER, S. (2010). Les policy transfer studies: analyse critique et perspectives, Critique internationale, n०3, p. 9-24.

DURIEUX, C. (1998), « La traduction, transfert linguistique ou transfert culturel?», Revue des lettres et de traduction, $n^{\circ} 4$, p. 13 29, consulté le 02/03/2017, http://documents.irevues.inist.fr/bitstream/handle/2042/41839/1998_ 4_13-29.pdf? sequence=3.

ESPAGNE, M. (2013), « La notion de transfert culturel », Revue Sciences/Lettres, $\mathrm{n}^{\circ} \quad 1, \quad$ consulté le 10/01/2017, http://rsl.revues.org/219

FARAHÂT, H. (1991), Harakat al-tarjama fi Misr, Dirâsa bibliyumîtriyya fî l-ittijâhât al-'adadiyya wa-l-naw'iyya, Le Caire, Al-markaz al-arabi lilnar wa al-tawzie.

GAUVIN, J. (1971), " Le discours de philosophie systématique. Expériences de lecture et recherches de structure», Langages, $\mathrm{n}^{\circ} 21$, Philosophie du language, sous la direction de Joseph Sumpf. pp. 88121, consulté le 23/01/2017, http:// www.persee.fr/doc/lgge_0458726x_1971_num_6_21_2080 
GENTES, A. (2009), « De la traduction comme médiation et création interlinguistique des Interactions», Revue des Interactions Humaines Médiatisées, Vol $10 \mathrm{~N}^{\circ} 1 / 2009$, consulté le 04/01/2017, http://europia.org/RIHM/V10N1/RIHM10(1-2)-Gentes.pdf

GUÉRY, F., (2005), « La traduction philosophique », Revue philosophique de la France et de l'étranger, 4/2005 (Tome 130), p. 467-468, http://www.cairn.info/revue-philosophique-20054-page-467.htm

HEILBRON, J., et G. SAPIRO (2002), « La traduction littéraire, un objet sociologique $»$, Actes de la recherche en sciences sociales, 4/2002 ( $\mathrm{n}^{\mathrm{o}}$ 144), p. 3-5, consulté le 02/03/2017, http://www.cairn.info/revue-actes-de-la-recherche-en-sciencessociales-2002-4-page-3.htm

HERSENT, J.-F. (2007), « Traduire : rencontre ou affrontement entre cultures ?», Hermès, La Revue, 3/2007, n 49, p. 157-167 http://www.cairn.info/revue-hermes-la-revue-2007-3-page-157.htm

JACQUEMOND, R.

(1991), « L'édition d'ouvrages traduits du français en Égypte: pour un point de vue biculturel », Égypte/Monde arabe, Première série, 5/ 1991, consulté le 05/ 01/ 2017, http://ema.revues.org/918

(1993), «Traductions croisées Égypte-France: stratégies de traduction et échange culturel inégal », Revue Égypte/Monde arabe, Première série, $15-16$, p. 183-296, mis en ligne le 08/07/2008, consulté le 10/03/2016, http://ema.revues.org/1109 (2007), «Les Arabes et la traduction: petite déconstruction d'une idée reçue », La pensée de midi, 2/2007 ( $\left.\mathrm{N}^{\circ} 21\right)$, p. 177-184.

(2010), " Les traductions arabes de Pierre Bourdieu», Arabica, T.57, Fasc.5/6 (2010), p. 559-588, consulté le 12/10/2015, http://www.jstor.org/stable/25782634

(2014), « Les flux de traduction de et vers l'arabe», Bibliodiversity-Translation and Globalisation, Févier 2014, p. 916 , consulté le $12 / 10 / 2015$ 
http://www.academia.edu/29688096/Les_flux_de_traduction_de_et vers_larabe

JĀNJAR, M.-S. (2009), Texte de la conférence donnée à l'Université Saint Joseph lors de la journée de réflexion : « Beyrouth, carrefour de la traduction », le 19 novembre 2009, consulté le 10/09/2016 http://www.transeuropeennes.eu/fr/articles/221/Traduction_et_consti tution_de_nouveaux_champs_des_savoirs_en_langue_arabe

LADMIRAL, J.R. (2006), « Esquisses conceptuelles, encore...», Palimpsestes, Revue de traduction, (Hors série), p.131-144, mis en ligne le 01/09/2008, consulté le 12/03/2017, http://palimpsestes.revues.org/390 (1981), " Éléments de traduction philosophique 》, Langue française, $\mathrm{n}^{\circ} 51$, La traduction, p. 19-34, consulté le 10/01/2017, http://www.persee.fr/doc/lfr_0023-8368_1981_num_51_1_5095

(2010), «Traduction philosophique et traduction spécialisée, même combat?», Synergies Tunisie, $\mathrm{n}^{\circ} 2-2010$, p. 11-30, https://gerflint.fr/Base/Tunisie2/ladmiral.pdf

MOGHITH, A. (1997), « Marxisme égyptien et marxisme occidental : traduction et idéologie », Égypte/Monde arabe, Première série, 30-31 | 1997, consulté le 06/01/2017. http://ema.revues.org/1600

POIRIER, P. et GENÊT, P. (2014), « La fonction éditoriale et ses défis», in Vitali-Rosati, M., \& Sinatra, M. E. (dir.), Pratiques de l'édition numérique, Montréal, Presses de l'Université de Montréal, p.15-29, consulté le 13/03/2017, http://books.openedition.org/pum $/ 312$

PONCHARAL, B. (2006) traduit de l'anglais, Recommandations pour la traduction des textes de sciences humaines, New York, American Council of Learned Societies, http://www.acls.org/sstp_guide_french.pdf

PYM, A. POUPAUD, S. TORRES SIMÓN, E. (2009). « Finding Translations. On the Use of Bibliographical Databases in Translation History », Meta, ${ }^{\circ}$ 54(2), p. 264-278. 
RINCK, F. (2010), " L'analyse linguistique des enjeux de connaissance dans le discours

scientifique. Un état des lieux », Revue d'anthropologie des connaissances, 2010/3, (Vol 4, n $\left.{ }^{\circ} 3\right)$, p. 427-450, consulté le 01/11/2016, http://www.cairn.info/revue-anthropologie-desconnaissances-2010-3-page-427.htm

ROCHLITZ, R. (2001), « Traduire les sciences humaines », Raisons politiques, 2001/2 ( ${ }^{\circ} 2$ ), p. 65-77, consulté le 19/10/2016, http://www.cairn.info/revue-raisons-politiques-2001-2-page-65.htm

SAPIRO, G.

(2008), «Normes de traduction et contraintes sociales», in A. Pym, M. Shlesing et D. Simeoni, Beyond descriptive translation : Studies: Investigations in homage to Gideon Toury, Amesterdam/Philadelphia, John Benjamins, p.199-208 (2012), « La circulation des sciences humaines et sociales en traduction : enjeux et obstacles à l'heure de la globalisation », Traduire, $\mathrm{n}^{\circ}$ 227, mis en ligne le 01/12/2014, consulté le 30/10/2016, http://traduire.revues.org/465

(2014), (sous la dir.), Sciences humaines en traduction Les livres français aux États-Unis, au Royaume-Uni et en Argentine, Étude réalisée par le Centre européen de sociologie et de sciences politiques (Paris) dans le cadre d'une convention avec l'Institut français, Paris, Institut Français, consulté le 30/09/2016

http://www.institutfrancais.com/fr/actualites/traduction-scienceshumaines

VARLET, E. (2010), « Les flux de traduction français-arabe en egypte et au machreq (1985-2010)», consulté le 02/01/2017, http://www.transeuropeennes.eu/ressources/pdfs/TEM2010 francais arabe Emmanuel_VARLET_34.pdf

Sites des bases de données bibliographiques

Centre national de traduction

http://nct.gov.eg/ 
Index Translationum - World Bibliography of Translation www.unesco.org/culture/xtrans/

Union des bibliothèques des universités égyptiennes

www.eulc.edu.eg/

Bibliothèque centrale de l'université du Caire

lis.cl.cu.edu.eg 


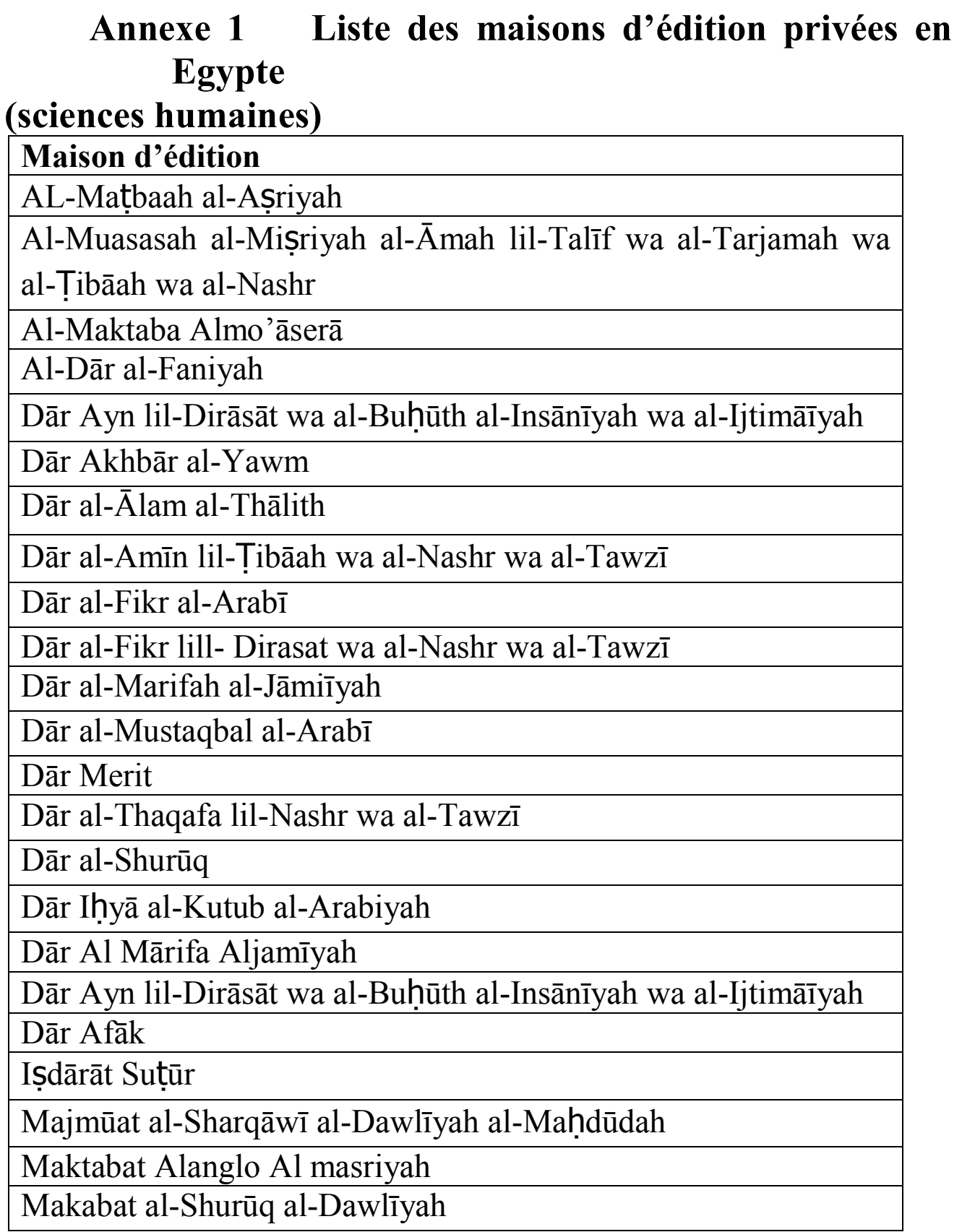




\begin{tabular}{|l|}
\hline Maktabat Mișr \\
\hline Maktabat Madbūlī \\
\hline Markaz al-Buhūūth al-Arabīyah wa al-Ifrīqīyah \\
\hline Markaz al-Maḥūsah lil-Nashr \\
\hline Muasasat Hendawi \\
\hline Munshaat al-Maārif \\
\hline Sīnā lil-Nashr \\
\hline
\end{tabular}

Annexe 2 Echantillon des publications du Centre national de traduction

\begin{tabular}{|c|c|c|c|c|}
\hline Auteur & Titre français & $\begin{array}{l}\text { Traducte } \\
\text { ur }\end{array}$ & Titre arabe & Domaine \\
\hline $\begin{array}{l}\text { Borgeaud, } \\
\text { Philippe }\end{array}$ & $\begin{array}{lr}\begin{array}{l}\text { Aux origines } \\
\text { l'histoire } \\
\text { religions } \\
\text { Seuil, 2004 }\end{array} \\
\text { des } \\
\end{array}$ & $\begin{array}{l}\text { Fawzeya } \\
\text { Elashmawy }\end{array}$ & منابع تاريخ الأديان & Histoire \\
\hline $\begin{array}{l}\text { Goetschel, } \\
\text { Pascale et } \\
\text { Loyer, } \\
\text { Emmanuelle }\end{array}$ & $\begin{array}{l}\text { Histoire culturelle de } \\
\text { la France de la Belle } \\
\text { Époque à nos jours }\end{array}$ & مصطفى ماهر & 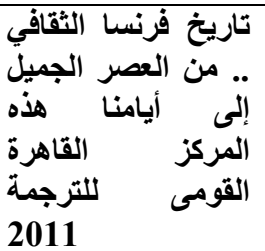 & $\begin{array}{l}\text { Histoire, } \\
\text { civilisation }\end{array}$ \\
\hline $\begin{array}{l}\text { Vinck, } \\
\text { Dominique }\end{array}$ & $\begin{array}{lr}\text { Sociologie } & \text { des } \\
\text { Sciences, } & \text { Paris, } \\
\text { Armand Colin, } & 1995 .\end{array}$ & ماجدة أباظة & علم اجتماع الطاهوم: المركز & $\begin{array}{l}\text { Sciences } \\
\text { sociales }\end{array}$ \\
\hline $\begin{array}{l}\text { Copleston, } \\
\text { Frederic }\end{array}$ & $\begin{array}{l}\text { A History of } \\
\text { Philosophy } \\
\text { Volume IV: } \\
\text { Descartes to Leibniz }\end{array}$ & $\begin{array}{l}\text { Saiid, } \\
\text { Tawfik }\end{array}$ & 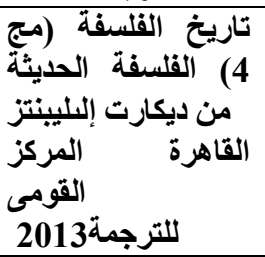 & Philosophie \\
\hline $\begin{array}{l}\text { Casanova, } \\
\text { Pascale }\end{array}$ & $\begin{array}{l}\text { La République } \\
\text { mondiale des lettres, } \\
\text { Paris, Seuil, } 2008\end{array}$ & $\begin{array}{ll}\text { Amal } & \text { El- } \\
\text { Sabban } & \end{array}$ & الجمهورية العادية القالمية & $\begin{array}{l}\text { Littérature, } \\
\text { culture }\end{array}$ \\
\hline
\end{tabular}




\begin{tabular}{|c|c|c|c|c|}
\hline T.Z. Lavine & $\begin{array}{l}\text { From Socrates to } \\
\text { Sartre : The } \\
\text { Philosophic quest, } \\
\text { Bantam, unknown } \\
\text { edition, 1985 }\end{array}$ & $\begin{array}{l}\text { Achraf } \\
\text { Mohamad } \\
\text { Alkilani }\end{array}$ & 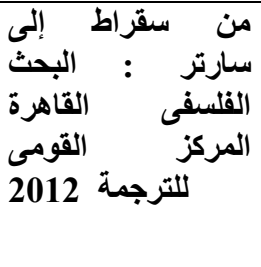 & Philosophie \\
\hline
\end{tabular}

Annexe 3 Liste des traducteurs dans le corpus des sciences humaines

(Philosophie, sociologie, psychologie, histoire)

\begin{tabular}{|c|c|}
\hline Nom du traducteur & Nom du traducteur \\
\hline Al-Siba' i, Bashir & Maher, Moustafa \\
\hline Abaza, Magda & Maḥmūd, Abd al-Ḥalīm; \\
\hline Abd Allāh, Șūfī; & Mandour, Mohamad \\
\hline Abdel-Aziz, Aïda & Moghuith, Anwar \\
\hline Abdel-Hamid, Nahed & Nabil Saad \\
\hline Alkilani, Achraf Mohamad & Nașr, Fāțimah \\
\hline Al-Kurdī, Mohamad & Nayel, Hossam \\
\hline Al-Khuḍīīi, Maḥmūd Maḥammad & Othman, Amin \\
\hline Asfour, Jaber & Qasem, Mahmoud \\
\hline Elashmawy, Fawzeya & Salāmah, Lațīf Mușțafā \\
\hline Al-Zawawi, Baghoura & Sabban, Amal \\
\hline Atteya, Ahmad Abdel Mooty & Sobhy, Camelia \\
\hline Badawi, Mohamad Elsayed & Taher, Hamed \\
\hline El-Toukhy, Dalia & Tolba, Mona \\
\hline Fatḥī, Ībrāhīm & Yacout, Ragaa \\
\hline Hamzé, Hassan & Zakaria, Fouad \\
\hline Huwaydī, Yaḥyā & Zikrī, Abū Bakr \\
\hline Kalfet, Khalil & Maḥmūd, Abd al-Halīm; \\
\hline Khalil, Ahmad Khalil & Mandour, Mohamad \\
\hline Labib, Mostafa Maher & Zītar, Ādel \\
\hline Lūqā, NaẒmī & Maḥmūd, Abd al-Halīm \\
\hline
\end{tabular}

